\title{
A elitização da educação pública: não é para todo mundo e nem para todo lugar
}

Dimitri Silva Sobral ${ }^{1}$

\section{Resumo:}

Após quase uma década da primeira implementação da lei de cotas e políticas de ações afirmativas no Brasil, muito ainda se discute sobre a democratização do acesso à educação pública. A discussão não deixa de ser pertinente quando o assunto é o ensino médio, especialmente em uma metrópole tão desigual como a do Rio de Janeiro. Nesse cenário, o presente trabalho visa discutir, com a ajuda de um estudo de caso, como a secretaria municipal de educação carioca atua na contramão das medidas de democratização do acesso ao ensino público, intensificando modelos de bonificação pautados na desigualdade. A metodologia consistiu na coleta de dados em campo, visitando algumas instituições estudadas, realizando entrevistas semi-estruturadas e orientadas, especialmente, pelos conceitos de prestígio escolar (Da Costa, 2008) e direito à cidade (Carlos, 2005), sistematizados com o trabalho de Bourdieu (2003), que disserta sobre a capacidade do sistema escolar público ser um meio de manutenção das desigualdades sociais.

Palavras-chave: democratização; educação; desigualdade; prestígio escolar.

\begin{abstract}
:
After almost a decade since the first act of the access democratization law in Brazil, there is a lot of discussion about the equality of access to public school. This topic is important as well when we talk about high school, especially in Rio de Janeiro, a very injustice city. Then, this research intends to discuss, with a study case, how the education department of Rio is acting against the democratization of public school access, increasing inequality models. The methodology concerns in search primary and secondary data, realizing semi-structured interviews oriented by the concepts of school prestige (Da Costa, 2008) and right to the city (Carlos, 2005), arguing with Bourdieu (2003), when discussing the school system as a tool that keeps the social inequality.
\end{abstract}

Keywords: democratization; education; inequality; school prestige.

${ }^{1}$ Universidade Federal do Rio de Janeiro. Mestrando no Programa de Pós-graduação em Geografia (PPGG/UFRJ). Email: dimitri.sobral@gmail.com 


\section{Introdução}

A premissa e a principal motivação do presente trabalho residem no contexto em que a educação brasileira se situa: passados 13 anos da primeira lei de políticas de ações afirmativas no estado do Rio de Janeiro (Lei 4151/2003) e 8 anos da obrigatoriedade da reserva de 50\% de vagas oriundas dessas ações em processos seletivos na educação pública federal (Lei no 12.711/2012), muito se discute sobre a eficiência e até mesmo a necessidade dessas leis. Não obstante, os setores mais conservadores da sociedade costumam sustentar a ideia da meritocracia, bem como do acesso equânime e universal à educação.

Bourdieu (2003) aponta, tomando como exemplo o caso francês, que o sistema escolar ratifica e conserva desigualdades sociais. O citado autor parte da premissa da escola ser um instrumento persuasivo quanto à possibilidade de ascensão social, porém aborda que sua persuasão é ilusória. Partindo desse rumo da discussão, pode parecer que, a fim de democratizar o acesso à educação pública, as leis de políticas de ações afirmativas bastariam para um país como o Brasil, por exemplo, aniquilando, com certa obviedade, o argumento daqueles que clamam a existência de uma meritocracia.

No entanto, segundo Da Costa et. al. (2012), o sistema educacional brasileiro é estratificado, sobretudo o ensino fundamental II em escolas municipais. A cidade do Rio de Janeiro, por assumir quase homogeneamente esse segmento entre as escolas públicas, apresenta consideráveis contradições no que tange o acesso e à distribuição de seus alunos. Corroborando com Bourdieu (2003), o destino da matrícula dos filhos e filhas de pais oriundos das classes populares tende a não ser uma escolha, e sim, um condicionamento induzido pelo poder público. Nesse sentido, no caso carioca, a secretaria municipal de educação (SME) utiliza-se de instrumentos de diferenciações entre suas escolas, como a Prova Brasil e o IDEB (Índice de Desenvolvimento da Educação Básica) que influenciam na opinião pública, sendo classificadas à grosso modo como "escolas boas", consequentemente aquelas que terão maior repercussão positiva e procura por vagas, consideradas o suprassumo, ainda que a uma escala de alcance reduzida a um bairro ou microrregião, ou "escolas ruins", as que terão repercussões negativas, conforme aponta Da Costa (2008) em seu conceito chamado de Prestígio Escolar. 
Costa, Prado e Rosistolato (2012), ainda identificam que as Coordenadorias Regionais de Educação (CREs) do município do Rio de Janeiro se utilizam das repercussões sobre as "escolas boas" para atribuir burocracias pouco claras quanto aos critérios para matrícula nas mesmas, repelindo publicamente a própria ideia do acesso a todos. Corroborando com Da Costa (2008), o sistema educacional público é composto por elites, ainda que fugindo de uma definição clássica, que são detentoras de oportunidades e recursos pouco acessíveis às "massas", em disputas pelo controle de tais recursos, os quais conferem oportunidades vantajosas de poder, prestígio e riqueza. Não obstante, pode, portanto, ser considerado um sistema com características de injustiça social, levando em conta a ausência dos critérios sintetizados por Schlosberg (2009) como a distribuição, reconhecimento, capacidade e participação democrática da sociedade. "O sistema não é equilibrado e não pode ser considerado equânime" (COSTA, PRADO e ROSISTOLATO, 2012, p. 170)

No mesmo sentido, é possível inserir, a partir de Corrêa (1989) e Costa (2010), a cidade do Rio de Janeiro como lócus de um intenso processo de exclusão social e precarização territorial, ou seja, sustenta uma divisão espacial entre diferentes classes sociais, onde o Estado atua direta e indiretamente para manter esse sistema, como aparenta ser o caso na educação pública.

[...] continuamos tomando o sistema escolar como um fator de mobilidade social, quando, ao contrário, tudo tende a mostrar que ele é um dos fatores mais eficazes de conservação social, pois fornece a aparência de legitimidade às desigualdades sociais, e sanciona a herança cultural e o dom social tratado como dom natural. (BOURDIEU, 2003, p. 41)

[...] a cidade também é o lugar dos conflitos que surgem como reivindicação, ou em torno da luta pelo direito à cidade, obrigando-nos a considerar, em sua radicalidade, a transformação da sociedade porque este é o conteúdo do direito à cidade. Nessa condição, "direito à cidade" introduz o negativo - a revolta da sociedade contra aquilo que segrega, afasta, impede a realização da vida na cidade, e com isso a interrogação sobre a realidade como condição para a construção de um projeto futuro. (CARLOS, 2005, p 227)

Dada a contextualização, o presente trabalho visa examinar, com a ajuda de um estudo de caso, como a educação pública pode ser um instrumento de ratificação ou intensificação das desigualdades sociais. 
O estudo de caso, por sua vez, será aplicado a uma complexidade ainda maior, pois envolve as matrizes federal, representada pelo Centro Federal de Educação Tecnológica Celso Suckow da Fonseca (CEFET/RJ), e municipal, representada pela $2^{a}$ Coordenadoria Regional de Educação ( $\left.2^{a} \mathrm{CRE}\right)$. As instituições são responsáveis pelo denominado Projeto Turma Cidadã, um curso Pré-técnico social, em formato de projeto de extensão entre o CEFET/RJ, localizado no bairro do Maracanã, e a coordenadoria de educação abrangente da área. A iniciativa surgiu por uma demanda que a própria instituição federal constatou, pois, passados os primeiros dois anos após a adesão ao sistema de ação afirmativa da Lei no $12.711 / 2012$, o número de alunos jubilados aumentou consideravelmente, segundo seu Departamento de Ensino Médio e Técnico (DEMET/CEFET).

A fim de mitigar o citado problema, o CEFET propôs à Secretaria Municipal de Educação (SME) a criação do projeto. Para isso, com o início das atividades em 2017, a instituição federal dispõe de servidores, voluntários, extensionistas bolsistas e salas de aula para atender, por ano, 80 alunos potencialmente cotistas, ou seja, matriculados em escolas municipais em seu $9^{\circ}$ ano do ensino fundamental e que possam prestar o processo seletivo para ingresso no nível médio-técnico do CEFET. Segundo a instituição, o projeto é um prétécnico social que visa o nivelamento dos futuros alunos e promover extensão com a comunidade, por isso o convênio com a $2^{\text {a }} \mathrm{CRE}$, coordenadoria de educação correspondente a bairros da Zona Sul e Grande Tijuca, na cidade do Rio de Janeiro (PORTAL CARIOCA DIGITAL, 2019). 
Mapa 1: área de estudo - abrangência da $2^{a}$ CRE e localização do CEFET.

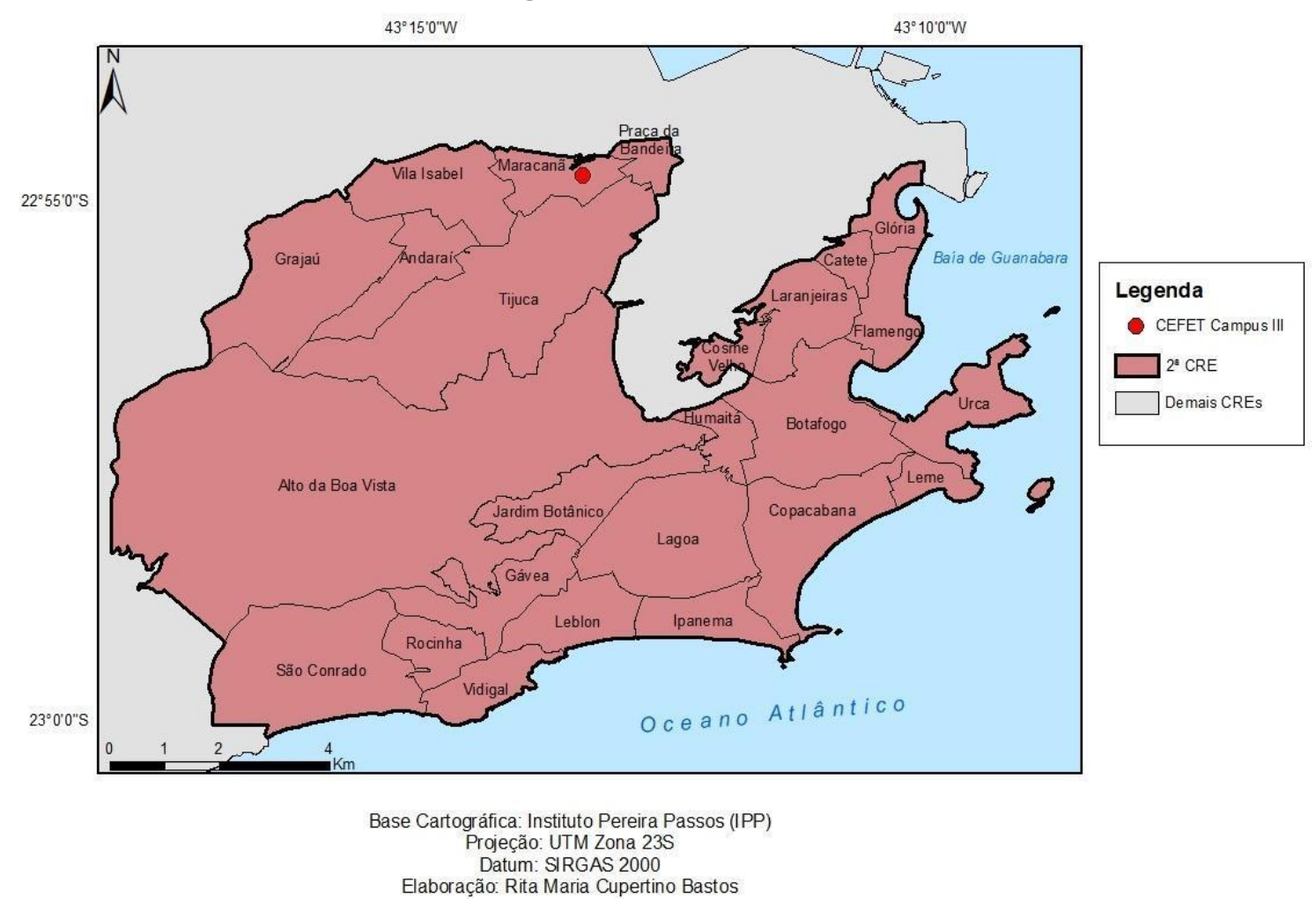

Nesse sentido, portanto, o presente trabalho visa examinar, com a ajuda do estudo de caso sobre a Turma Cidadã, o Pré-técnico social do CEFET, se a educação pode ser um instrumento de ratificação ou intensificação das desigualdades sociais. Como objetivos específicos, o trabalho irá: levantar quais escolas fazem parte do projeto e por que, bem como suas localizações e a quantidade de alunos cedidos; identificar os critérios para a seleção do alunado anual do projeto, quem os elabora e quais implicações sócio-espaciais podem oferecer; analisar o êxito do projeto desde seu início, em 2017, até o momento, verificando a quantidade de estudantes que foram aprovados no processo seletivo do CEFET e suas respectivas permanências na instituição.

\section{Metodologia}

A metodologia do presente trabalho foi dividida em três levantamentos: o bibliográfico, visando a articulação da pesquisa às bases teóricas referentes aos conceitos de Território, Espaço e Justiça Social no campo da ciência geográfica. Não obstante, no campo educacional, os conceitos a serem articulados serão prestígio escolar e sistema educacional estratificado. A articulação entre geografia e educação é feita visando a complementação sobre o tema do acesso à escola pública, tendo como plano de fundo, o espaço urbano da cidade do Rio de Janeiro. 
Outro levantamento será feito a partir da coleta de dados mediante trabalhos de campo, visando informações gerais sobre a iniciativa, bem como as mais específicas, sendo obtidas por meio de entrevistas semi-estruturadas à coordenação do Pré-técnico social do CEFET/RJ. A partir dos procedimentos bibliográficos, as idas a campo visam a compreensão sobre os mecanismos de seleção das escolas municipais integrantes do projeto.

Por fim, também se apresenta neste trabalho o levantamento de dados referentes à Secretaria Municipal de Educação, como a quantidade de escolas que tenham condições de participar do projeto, suas localizações e outras informações complementares. Para isso, serão utilizados o portal carioca digital, onde a SME disponibiliza a localização das escolas por região administrativa, além do Censo Escolar, a fim de alcançar informações relativas ao desempenho das instituições participantes do convênio em avaliações públicas como Prova Brasil e IDEB, sob a ótica do conceito de prestígio escolar, abordado por Da Costa (2008).

\section{Discussão teórico-conceitual}

Bourdieu (2003) aponta para uma certa superficialidade no que diz respeito às análises sobre escolas públicas serem homogeneamente de má qualidade e, não obstante, indica que há hierarquias socialmente conhecidas entre essas instituições. Nesse sentido, o autor argumenta que o poder público atua de maneira distinta na gestão escolar e, consequentemente na distribuição de seus alunos, mantendo um sistema de valores implícito e interiorizado pela sociedade, levando a uma quase conformação de uma realidade desigual e imutável. O citado autor ainda aponta que, nesse sentido, sendo a escola pública alvo de uma procura maior entre as classes desfavorecidas, e concomitantemente tratada de maneira desigual pelo Estado, privilegiando umas em detrimento de outras, a desigualdade social não só mantida, mas é intensificada, marginalizando ainda mais os mais pobres e mantendo as diferenças entre classes sociais. Da Costa, Do Prado e Rosistolato (2012) corroboram com essa vertente, acrescentando ainda que as principais "fugas" desse sistema são oriundas de práticas como nepotismo, troca de favores ou até mesmo votos, chamado pelos autores como "algum conhecimento" que os pais tenham para matricularem seus filhos em instituições municipais de certo renome positivo, o "prestígio escolar" (DA COSTA, 2008) ainda que em escala local, devido, principalmente, a 
resultados dessas escolas em avaliações nacionais como o IDEB. Complementarmente, entende-se prestígio escolar como: “[...] elementos que conferem diferenciação a estabelecimentos de ensino que, submetidos à mesma autoridade e às mesmas regras, integrando os mesmos sistemas $\mathrm{e}$ dispondo de recursos equivalentes, apresentam considerável disparidade em muitos aspectos e gozam de reputações claramente opostas", conforme Da Costa (2008, p. 455).

A partir da discussão feita por Bourdieu (2003) e das estratégias debatidas por Da Costa, Prado e Rosistolato (2012), é possível, portanto, considerar a escola pública um objeto do espaço social a ser conquistado e ocupado e, para isso, em um sistema educacional estratificado, estratégias são necessárias. Do ponto de vista geográfico, portanto, estamos falando de um recurso que é alvo de disputa por oferecer a possibilidade de obtenção do capital cultural.

"Seja no campo seja na cidade, as novas chances da ordem competitiva se abrem para os segmentos mais capazes de arregimentar maior qualificação comparativa do trabalho, poupança e mobilidade espacial e ocupacional. Os imigrantes e os segmentos mais cultos ou semi-instruídos de origem nacional são os candidatos naturais a ocuparem os novos espaços.

Abaixo do segmento dos novos incluídos no mercado competitivo existiria uma plebe nacional composta por brancos que vinham do campo para as cidades e para quem os interstícios da nova ordem eram de qualquer modo um ganho em relação à miséria material e moral da dependência pessoal. Mais abaixo ainda, dá-se a constituição histórica daquilo que chamo de 'ralé brasileira': composta pelos negros recém-libertos e por mulatos e mestiços de toda ordem para quem a nova condição era apenas uma nova forma de degradação. A submersão na lavoura de subsistência ou a formação das favelas nas grandes cidades passam a ser o destino reservado pelo seu abandono". (SOUZA, 2017. p. 47)

No caso do presente estudo de caso, o que parece se apresentar em um primeiro momento como oportunidade a classes sociais mais pobres, é, por outro lado, a reprodução de um sistema educacional estratificado, baseado em uma ilusão meritocrática e ratificadora das desigualdades sociais.

"Talvez estudos como o que temos realizado auxiliem a compreender a crítica situação de um amplo sistema educacional que logrou incorporar recentemente a quase totalidade de seu público potencial ao nível fundamental de ensino, mas que guarda abismos em todos os níveis escolares e, consequentemente, nas oportunidades de integração socioprofissional de gerações à sociedade em geral”. (DA COSTA, 2008, p. 456).

Nesse sentido, é pertinente considerar que a camada da sociedade que detém recursos pouco acessíveis à maioria das pessoas, é, portanto, uma elite, especialmente em contextos em 
que as disputas pelo acesso à educação em escolas como o CEFET, são desiguais e oferecem oportunidades vantajosas de poder, prestígio e ascensão social, conforme discute $\mathrm{Da}$ Costa (2008). Não obstante, o conceito de território se mostra fundamental na compreensão geográfica do acesso a recursos no espaço social.

Segundo Souza (2013) o território pode ser entendido como a expressão espacial das relações de poder. Nesse sentido, ele configura um modo como as relações sociais se dão, ou seja, quem e por que domina, controla, governa, influencia ou apropria, sendo o espaço o substrato referencial da ocorrência dessas relações. As análises, portanto, podem ser em uma escala temporal (dia, ano, década, mês, por exemplo) e em uma espacial (rua, bloco econômico, por exemplo). É importante ainda ressaltar que o território não é o poder em si, mas sim a sua expressão no espaço de quem o detém e, por consequência, quem não o detém, configurando assim, a territorialização e a desterritorialização. Portanto, no caso do acesso às escolas públicas municipais do Rio de Janeiro, as escolas sem o prestígio escolar (DA COSTA, 2008) são aquelas instituições que restam àqueles grupos com menos possibilidades de alternativas, ou seja, os desterritorializados, na perspectiva de Souza (2013).

Por outro lado, levando em consideração não apenas a produção desigual do espaço urbano e a pouca (quando há) margem de manobra dos grupos sociais excluídos apontados por Corrêa (1989), não sendo diferente inclusive no acesso à educação, conforme citado anteriormente, mas também a complexidade das relações sociais desiguais, o conceito de multiterritorialidade (COSTA, 2007) se mostra como o mais apropriado para o presente fenômeno. Segundo o autor, não há desterritorialização sem reterritorialização, pois a vivência nos diferentes territórios se apresenta de forma concomitante, ou seja, há uma multiplicidade de territórios no mesmo espaço, com atuações distintas e sobrepostas por meio de seus diferentes grupos. Nesse sentido, aqueles que perdem ou não possuem um determinado território, em uma dimensão social, são os grupos mais destituídos, os precariamente territorializados (COSTA, 2007; 2010).

Ainda segundo Costa (2007), todo território é funcional e simbólico. Seus símbolos, portanto, são os componentes representativos do poder, ou seja, a territorialidade. Para o autor, ela serve para criar e manter grande parte do contexto geográfico que vivemos e damos 
significado, assim como para criar e manter a ordem. Para Souza (2013), a ideia de ordem está associada com alguma frequência ao conceito de organização espacial, apontada também por Corrêa (1995) como a divisão espacial do trabalho, a disposição e distribuição espacial da infraestrutura técnica (transporte, água, energia) e espacial (postos de saúde, padrão residencial e as escolas). Ainda para Souza (2013), a estrutura da organização espacial é feita para a (re)produção de uma ordem heterônoma presente nas cidades do sistema capitalista e facilitada pelo Estado. A heteronomia, nesse sentido, é a verticalização das relações sociais, ou seja, a imposição das desigualdades e a redução da liberdade e autonomia dos grupos marginalizados nessas relações.

Um exemplo sobre o sistema heterônomo também presente na educação é discutido por Bourdieu (2003) ao questionar se o local de estudo das crianças de origem popular é uma escolha ou um condicionamento imposto. Para o autor, há consideráveis diferenças no que tange a visão que os grupos sociais excluídos (ou precariamente territorializados, segundo Costa [2007; 2010]) têm sobre a educação. A classe média baixa ou de transição, nesse ponto de vista, acredita na ascensão social por meio de escolas melhores e incentiva o estudo de seus filhos. Por outro lado, os grupos ainda mais populares não creem na ascensão e transmitem o pensamento para os filhos, herdando a premissa do "isso não é para nós". Nesse sentido, para o autor, a escola é uma instituição aristocrata e conservadora, pois trata os diferentes igualmente e assume um tipo de aluno como o padrão de qualidade, normatizando e intensificando relações que, antes de tudo, são sociais.

O Rio de Janeiro, assim como o padrão seguido pelas cidades brasileiras, teve seu processo de urbanização de maneira intensa e acelerada (ABREU, 1987). Nesse sentido, para reprodução das relações entre classes nos moldes capitalistas, foi necessária a distribuição de áreas sociais segregadas, cujo acesso a recursos necessários à ascensão social é diferenciado (HARVEY, 1975).

Segundo Sposito (1988), o que norteia o entendimento da formação das cidades, por meio do processo de urbanização, possui correspondência direta com a divisão social e territorial do trabalho, portanto, correlata às dinâmicas da precarização territorial. Dizemos processo porque a urbanização se aplica de maneira histórica, material e, sobretudo social. 
Portanto, compreender a identidade da cidade é analisar o resultado cumulativo das transformações, destruições e reconstruções produzidas pela sociedade ao longo do tempo.

Segundo Corrêa (1989), o espaço urbano é fragmentado e articulado, reflexo da economia capitalista que o origina e o reproduz, sendo assim, um condicionante social. Nesse sentido, para entender a produção do espaço urbano, deve-se compreender a sociedade que o produz, ou seja, uma relação dialética, em que, a cidade é produzida pela sociedade e esta, se reproduz à medida em que se modifica o processo de produção e reprodução da cidade. Já Beaujeu-Garnier (1995), aponta que o ambiente urbano exerce grande influência em seus habitantes, transformando-os pouco a pouco com suas exigências como alimentação, matériasprimas e comércio, por exemplo. Tem o poder de difundir, bloquear ou favorecer os diversos impulsos na cidade, mas é reciprocamente utilizado e modelado pelo homem. Não obstante, é possível ratificar com os argumentos também trabalhados por Bourdieu (2003) que, sendo a escola uma parte da organização espacial heterônoma, ela é nos moldes capitalistas, um importante instrumento de manutenção da (des)ordem e da desigualdade. No mesmo sentido, se considerada como um meio de ascensão social em virtude das disputas por aquelas detentoras do prestígio escolar, como abordado por Da Costa (2008), ela pode ser também associada a um recurso espacial.

\section{As geografias do pré-técnico social}

O presente capítulo se propõe a dissertar sobre os dados coletados em trabalhos de campo realizados no CEFET Maracanã, Campus III, onde se localizam as disposições de funcionamento do Projeto Turma Cidadã. Duas visitas foram realizadas: a primeira em 20 de maio de 2019 e a segunda em 14 de agosto do mesmo ano. O primeiro encontro visava contatos preliminares com a coordenação do Pré-técnico, apresentando a presente pesquisa e, não obstante, buscando dados sobre o quantitativo de escolas conveniadas e alunos cedidos, bem como informações referentes ao contexto de surgimento do projeto social e questões relacionadas ao convênio com a Secretaria Municipal de Educação. O segundo campo, 
portanto, foi feito visando questões originadas das análises dos dados concedidos pela coordenação neste primeiro encontro.

Inicialmente, a entrevista à coordenação se propôs a buscar elementos para compreender o contexto de surgimento e funcionamento do Pré-técnico social. A coordenação é dividida entre um servidor técnico administrativo e uma professora de educação física readaptada em função de apoio pedagógico, ambos trabalhadores do CEFET. Segundo eles, a ideia da criação de um pré-técnico social surgiu após os primeiros dois anos de turmas oriundas do processo seletivo em que se fez presente a política de cotas para alunos que visam o ingresso no primeiro ano do ensino médio-técnico integrado da instituição. A política adotada pelo CEFET está em acordo com a Lei no 12.711/2012, que discorre sobre a obrigatoriedade de todas instituições de ensino federais disponibilizarem 50\% de suas vagas em processos seletivos para candidatos oriundos da rede pública de ensino. Nesse sentido, portanto, a primeira turma já dentro da nova lei ingressou na instituição no ano de 2013. Em 2015, segundo o coordenador do pré-técnico, surgem os primeiros questionamentos internos no CEFET no que tange o novo público presente na escola, pois por conta de uma grande diferença nos resultados obtidos nas avaliações entre suas escolas antigas e a atual, o número de reprovações e, consequentemente, de jubilamentos (duas reprovações anuais consecutivas) teria aumentado drasticamente, segundo pesquisas feitas pelo Departamento de Ensino Médio e Técnico (DEMET) da unidade.

Ainda segundo o coordenador, algumas propostas de ação foram levantadas visando um equilíbrio entre o acesso e a permanência do novo público de alunos que agora ocupa o CEFET, uma escola que historicamente dispunha quase exclusivamente de estudantes oriundos de colégios renomados da rede particular de ensino, conforme aponta Souza (2016). Após longo tempo de discussões, a ideia da criação de um pré-técnico social para atender, pelo menos, a comunidade da Grande Tijuca foi levantada pelo corpo docente da instituição. A proposta visava um convênio com a Secretaria Municipal de Educação do Rio de Janeiro, especificamente sua $2^{a}$ Coordenadoria Regional, responsável pelas escolas públicas municipais na região da Grande Tijuca e da Zona sul. A intenção era que a CRE pudesse encaminhar alunos moradores das proximidades do CEFET para que pudessem assistir aulas das disciplinas 
básicas do ensino fundamental no Pré-Técnico Social, ministradas por professores do quadro permanente do ensino médio do CEFET, servidores administrativos licenciados em alguma das áreas e professores voluntários. A realização das atividades seria, portanto, no turno oposto aquele em que os alunos selecionados estudam regularmente em suas escolas. Assim, seria firmada a parceria em formato de Projeto de Extensão do Centro Federal com a comunidade de seu entorno.

A proposta, segundo a coordenação, foi levada por ele próprio à $2^{a} \mathrm{CRE}$ e prontamente aceita. Assim, o CEFET disponibilizou 80 vagas para estudantes em seu Pré-Técnico Social, divididas em 40 para o turno da manhã e 40 para o turno da tarde, tendo iniciado suas atividades no início do ano letivo de 2017. Ao fim do presente campo, a coordenação ofereceu dados que podem esclarecer as questões referentes ao número de escolas participantes, quantidade de estudantes selecionados por cada uma delas e o total de jubilamentos que justificariam a criação do convênio.

Gráfico 1: Número de vagas oferecidas para o concurso de acesso ao ensino médio.

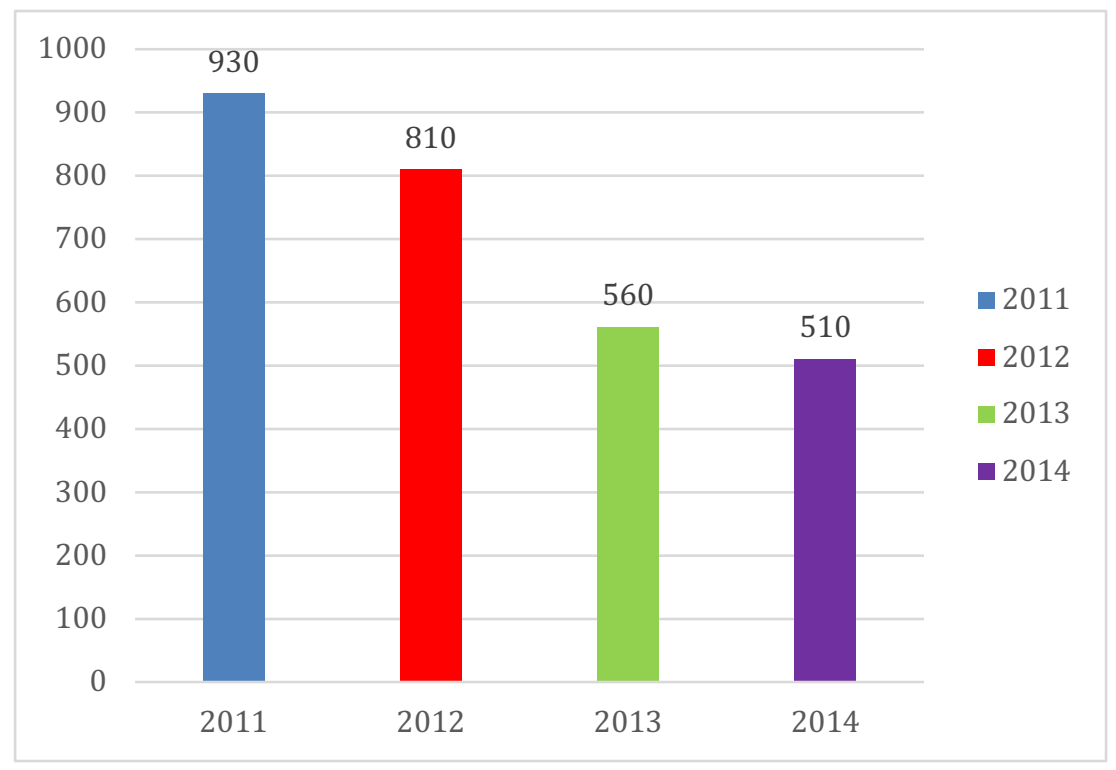

Fonte: DEMET-CEFET/RJ

Gráfico 2: Evasão e permanência no ensino médio integrado entre 2013 e 2015. 


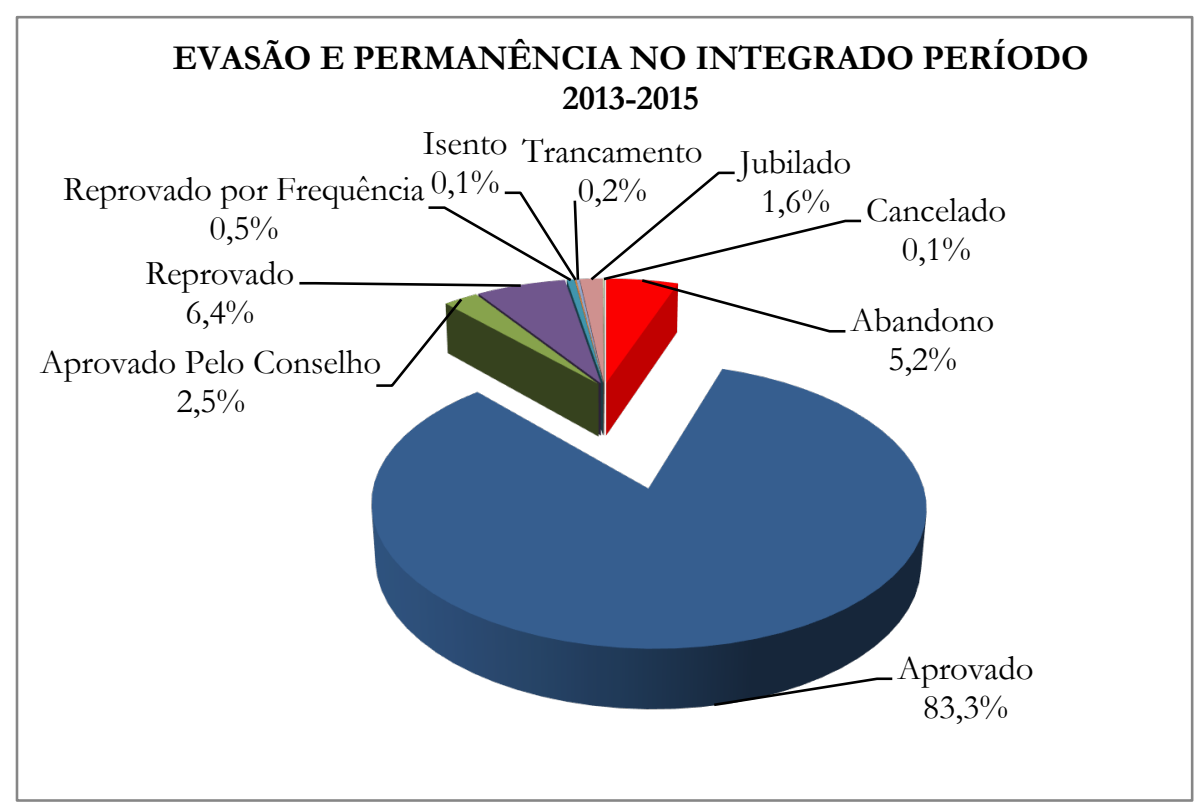

Fonte: DEMET-CEFET/RJ.

Os gráficos 1 e 2 representam, respectivamente, o número de vagas ofertadas para o ensino médio-técnico e o percentual dos números de evasão e permanência no CEFET Maracanã. Ambos foram elaborados e cedidos pelo Departamento de Ensino Médio e Técnico da instituição para a coordenação do Pré-Técnico Social, adquiridos pela presente pesquisa no primeiro trabalho de campo, conforme citado anteriormente. Analisando os dados supracitados, especialmente os concursos dos anos de 2012, 2013 e 2014, os três primeiros em acordo com a Lei $n^{0}$ 12.711/2012, é possível notar, em associação com o gráfico 2, que o número de estudantes jubilados nesse período de ingresso foi de 1,6\%. O universo, conforme o gráfico 1, é a soma entre os três citados anos, resultando em 1880 estudantes matriculados. Nesse sentido, o jubilamento de estudantes foi de aproximadamente 38 alunos em 3 anos. Apesar do aumento de reprovações consecutivas ter sido pauta de, conforme citado pela coordenação, frequentes reuniões e justificativa para a criação do próprio projeto de extensão, não foi possível obter os dados oficiais com o DEMET no período anterior à adesão ao sistema de cotas. Assim, os dados que o CEFET cedeu ao presente trabalho não se mostram condizentes com os argumentos utilizados para criação do convênio com a prefeitura.

Conforme citado anteriormente, através do primeiro contato em campo com a coordenação do Pré-Técnico Social, foi possível obter dados sobre o número de escolas envolvidas no projeto, bem como o número de estudantes selecionados por cada uma delas 
entre os anos de 2017, quando se formaram as primeiras duas turmas, e o de 2018. A partir da coleta dessas informações, foi possível constatar que apenas 8 escolas fizeram parte do convênio no período citado. A fim de elaborar uma relação com o universo total de alunos do $9^{\circ}$ ano do ensino fundamental de cada uma dessas escolas, foi necessário o acesso aos censos escolares.

Tabela 1: Escolas pertencentes ao projeto, número de alunos selecionados e total de matriculados nas mesmas instituições em 2017.

\begin{tabular}{|c|c|c|}
\hline ESCOLA & $\begin{array}{c}\mathbf{N}^{\circ} \text { de alunos no convênio em } \\
2017\end{array}$ & $\begin{array}{l}\text { Total de alunos no } 9^{\circ} \text { ano em } \\
2017\end{array}$ \\
\hline E.M. Orsina da Fonseca & 9 & 101 \\
\hline E.M. Francisco Cabrita & 10 & 63 \\
\hline E.M. Epitácio Pessoa & 7 & 36 \\
\hline E.M. Barão Itacurussá & 10 & 55 \\
\hline E.M. Madrid & 8 & 81 \\
\hline E.M. Francisco Manuel & 8 & 105 \\
\hline E.M. Gal Euclydes de Figueiredo & 8 & 66 \\
\hline E.M. Martin Luther King & 1 & 30 \\
\hline
\end{tabular}

Fonte: dados obtidos em campo; censo escolar 2017; organização autoral.

Tabela 2: Escolas pertencentes ao projeto, número de alunos selecionados e total de matriculados nas mesmas instituições em 2018.

\begin{tabular}{|l|c|c|}
\hline \multicolumn{1}{|c|}{ ESCOLA } & $\begin{array}{c}\mathbf{N}^{\mathbf{0}} \text { de alunos no convênio em } \\
\text { E.M. Orsina da Fonseca }\end{array}$ & $\begin{array}{c}\text { Total de alunos no } 9^{\mathbf{o}} \text { ano } \\
\text { em } 2018\end{array}$ \\
\hline E.M. Francisco Cabrita & 9 & 108 \\
\hline E.M. Epitácio Pessoa & 11 & 119 \\
\hline E.M. Barão Itacurussá & 8 & 48 \\
\hline E.M. Madrid & 10 & 54 \\
\hline E.M. Francisco Manuel & 10 & 110 \\
\hline E.M. Gal Euclydes de Figueiredo & 8 & 71 \\
\hline E.M. Martin Luther King & 5 & 47 \\
\hline
\end{tabular}

Fonte: dados obtidos em campo; censo escolar 2018; organização autoral.

Conforme as tabelas 1 e 2, o projeto contou com 8 escolas entre os anos de 2017 e 2018. No entanto, é possível notar grande disparidade entre o quantitativo total de alunos de $9^{\circ}$ ano por instituição e o número cedido ao pré-técnico social. Não obstante, também é possível constatar outras diferenças na própria distribuição de vagas por escola, como é visto na comparação entre a unidade Francisco Cabrita, com 10 estudantes em 2017 e 11 em 2018, ao passo que a Escola Municipal Martin Luther King cedeu o total de um único aluno entre os 
dois anos. Sob a ótica do sistema educacional estratificado na educação pública do Rio de Janeiro, abordado por Costa, Prado e Rosistolato (2012), fez-se necessário, portanto, um aprofundamento no que tange a distribuição espacial das escolas da Grande Tijuca e sua relação com a participação no convênio.

Segundo o Portal Carioca Digital, uma plataforma online da Secretaria Municipal de Educação do Rio de Janeiro que disponibiliza informações referentes aos seus serviços, a $2^{\mathrm{a}}$ CRE é responsável por um total de 153 unidades escolares entre a região da Grande Tijuca, Centro e parte da Zona Sul da Cidade. No entanto, apenas 16 estão localizadas na Grande Tijuca (Tijuca, Praça da Bandeira, Vila Isabel, Maracanã e Andaraî), o que o CEFET classifica como público alvo de seu projeto de extensão inicialmente.

Tabela 3: as escolas municipais da Grande Tijuca e a distância ao CEFET Maracanã.

\begin{tabular}{|c|c|c|}
\hline INSTITUIÇÃO & BAIRRO & Distância ao CEFET \\
\hline ESCOLA MUNICIPAL ORSINA DA FONSECA & Tijuca & $1,0 \mathrm{~km}$ \\
\hline ESCOLA MUNICIPAL REVERENDO MARTIN LUTHER KING & $\begin{array}{c}\text { Praça da } \\
\text { Bandeira }\end{array}$ & $1,7 \mathrm{~km}$ \\
\hline ESCOLA MUNICIPAL FRANCISCO CABRITA & Tijuca & $2,0 \mathrm{~km}$ \\
\hline ESCOLA MUNICIPAL MADRID & Vila Isabel & $2,2 \mathrm{~km}$ \\
\hline ESCOLA MUNICIPAL GENERAL EUCLYDES DE FIGUEIREDO & Tijuca & $2,3 \mathrm{~km}$ \\
\hline ESCOLA MUNICIPAL FRANCISCO MANUEL & Vila Isabel & $2,8 \mathrm{~km}$ \\
\hline ESCOLA MUNICIPAL REPUBLICA ARGENTINA & Vila Isabel & $3,0 \mathrm{~km}$ \\
\hline ESCOLA MUNICIPAL LAUDIMIA TROTTA & Tijuca & $3,4 \mathrm{~km}$ \\
\hline ESCOLA MUNICIPAL GENERAL DO EXERCITO HUMBERTO & Maracanã & $4,3 \mathrm{~km}$ \\
\hline DE SOUZA MELLO & Andaraí & $4,4 \mathrm{~km}$ \\
\hline ESCOLA MUNICIPAL PRESIDENTE JOAO GOULART & Tijuca & $4,4 \mathrm{~km}$ \\
\hline ESCOLA MUNICIPAL SOARES PEREIRA & Tijuca & $4,5 \mathrm{~km}$ \\
\hline ESCOLA MUNICIPAL BARAO DE ITACURUSSA & Andaraí & $5,0 \mathrm{~km}$ \\
\hline ESCOLA MUNICIPAL EPITACIO PESSOA & Vila Isabel & $5,5 \mathrm{~km}$ \\
\hline ESCOLA MUNICIPAL AFFONSO PENNA & Vila Isabel & $5,9 \mathrm{~km}$ \\
\hline ESCOLA MUNICIPAL EQUADOR & Vila Isabel & $8,9 \mathrm{~km}$ \\
\hline ESCOLA MUNICIPAL JORNALISTA ASSIS CHATEAUBRIAND
\end{tabular}

Legenda:

Situada na Grande Tijuca, mas não faz parte da parceria

Faz parte da parceria

Fonte: Google Earth.

As escolas participantes do convênio entre CEFET e $2^{a}$ CRE são, conforme a tabela 3 , as destacadas pela coloração mais escura. Analisando a distância delas até o Campus III do CEFET, na Rua General Canabarro, no Maracanã, onde são realizadas as atividades do pré- 
técnico social, por meio do Google Earth, é possível identificar que a proximidade não é, à priori, o principal critério para participação na parceria, tendo em vista que a E.M. Martin Luther King, apesar de se localizar a menos de 2 quilômetros do local do pré-técnico, só cedeu um aluno em 2017 e sequer cedeu algum em 2018.

Mapa 2: relação espacial entre as escolas contempladas e não contempladas pelo convênio CEFET-2 ${ }^{a}$ CRE.

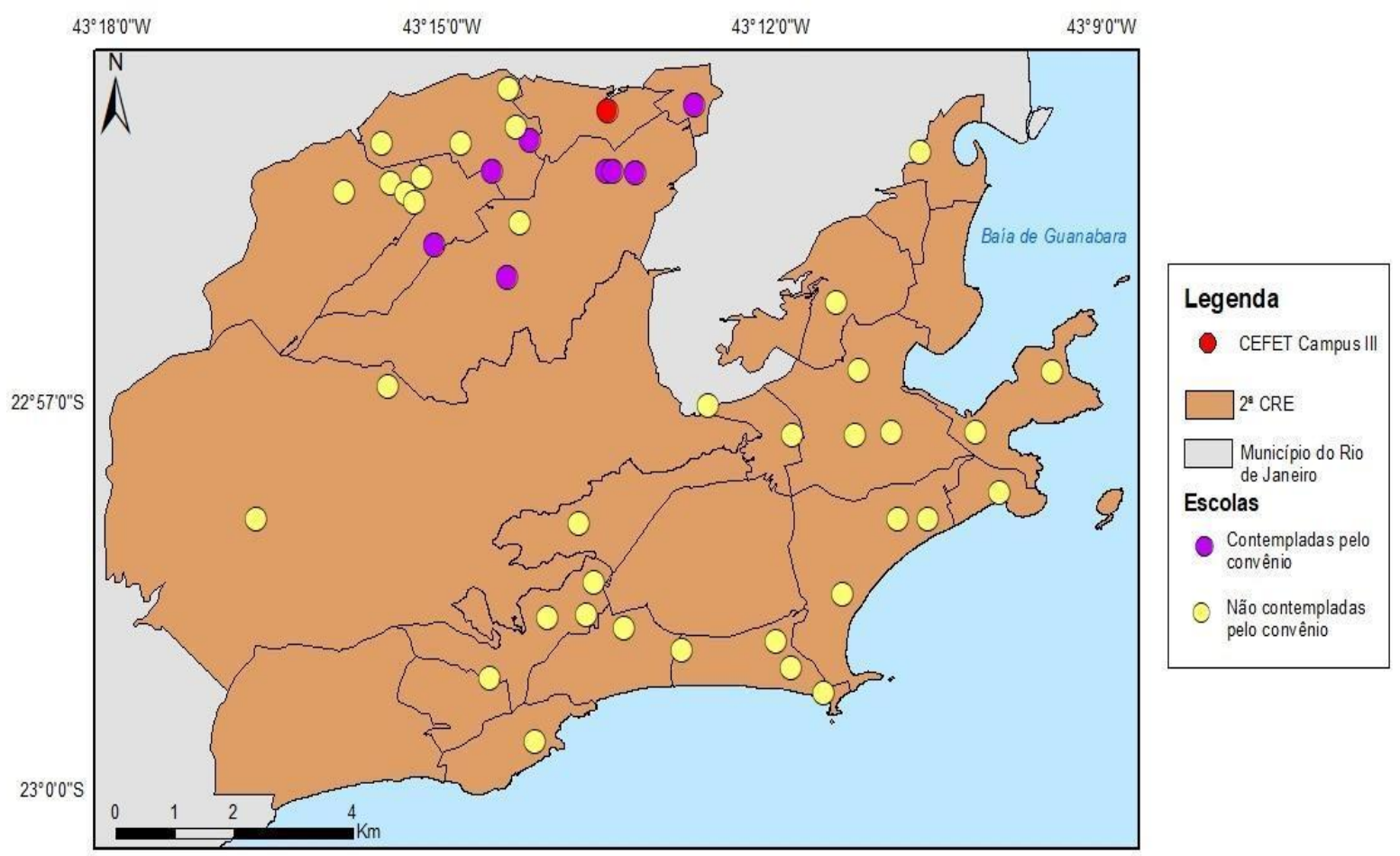

Base Cartográfica: Instituto Pereira Passos (IPP)
Projeção: UTM Zona 23S
Datum: SIRGAS 2000
Elaboração: Rita Maria Cupertino Bastos

Conforme é possível notar pela distribuição ilustrada pelo mapa 2, a distância (no caso, o trajeto por meio de transporte coletivo rodoviário), não determina a participação das escolas no convênio. Não obstante, é possível observar que dentre as instituições participantes representadas pela cor roxa - há, ainda, algumas que têm o deslocamento ao CEFET (representado pela cor vermelha) mais dificultoso do que outras que, embora mais próximas e com melhor possibilidade de deslocamento, não participam (representadas pela cor amarela). Nesse sentido, para compreender a lógica da distribuição de vagas e de interesses, foi necessário 
um aprofundamento na pesquisa, intensificando a análise dos dados coletados em campo, em plataformas como o portal Carioca e nos censos escolares.

\section{Os mecanismos de seleção do alunado}

Como já comentado na seção anterior, o segundo trabalho de campo nas dependências do pré-técnico social, no Campus III do CEFET Maracanã, foi realizado após a análise dos dados coletados em entrevista à coordenação do curso e de materiais fornecidos por ela. No entanto, conforme visto na análise sobre a localização das escolas e suas proximidades ao CEFET, foi possível notar dois pontos importantes: 1) a proximidade não é o principal critério adotado para a seleção das escolas participantes do convênio; 2) há uma contradição entre o interesse manifestado pelo CEFET em atender à comunidade escolar no entorno, pois além de atender escolas com razoável distância como as EM Barão de Itacurussá e Epitácio Pessoa, deixa de atender outras que se localizam ainda mais próximas como as EM República Argentina, Laudímia Trotta, General do Exército Humberto de Souza Mello, Presidente João Goulart e Soares Pereira. Portanto, o presente trabalho se propôs a utilizar o conceito de prestígio escolar, abordado por Costa (2008), para aprofundar as questões do segundo trabalho de campo à coordenação do pré-técnico.

Nesta segunda ida a campo, foi realizada outra entrevista semi-estruturada, com o intuito de compreender quais critérios foram levados em consideração para a seleção das escolas participantes do projeto, o número de alunos cedidos por cada uma e, principalmente, quais agentes eram os responsáveis por essa elaboração.

A coordenação do pré-técnico retomou a contextualização referente à criação da parceria, apontando que algumas reuniões ocorreram entre o fim de 2015 e durante o ano de 2016 com representantes do CEFET e da Secretaria Municipal de Educação. Segundo os coordenadores, o CEFET pretendia conceder à CRE a autonomia total para a escolha das escolas a serem inseridas no projeto, bem como para a seleção do alunado. No entanto, os estudantes deveriam manifestar interesse em estudar na instituição federal durante o ensino 
médio e, segundo a coordenação, em segundo plano, deveriam ter boas notas, sem especificarem, objetivamente, um número real quanto ao conceito dessa avaliação.

Entretanto, apesar da mencionada concessão de autonomia à SME para escolher os alunos, a coordenação do CEFET se mostrou surpresa ao observar os dados levantados pela presente pesquisa e notar que um número elevado de escolas municipais não estava sendo atendidas. Nesse sentido, os coordenadores não souberam informar precisamente qual o principal critério adotado pela prefeitura, mas que, especificamente no caso da Escola Municipal Martin Luther King, situada a menos de 2 quilômetros do Campus, a coordenação afirmou ter pedido a inserção dessa unidade no projeto, porém recebeu apenas um estudante pela CRE.

\subsection{O IDEB como fator determinante para as escolhas da Secretaria Municipal de Educação}

Ao longo da pesquisa, analisando os dados obtidos no primeiro trabalho de campo e, posteriormente, constatar que a distância por si só não se apresentou como fator determinante para a participação das escolas no projeto Turma Cidadã, o conceito de prestígio escolar (COSTA, 2008), se mostrou pertinente em uma hipótese em que, provavelmente, as escolhas da SME, através da $2^{a} \mathrm{CRE}$, foram orientadas por resultados que as escolas tenham alcançado em avaliações educacionais nacionais, como a Prova Brasil e o IDEB, por exemplo.

Segundo Da Costa (2008), esses resultados não interferem diretamente em pautas como verbas destinadas a mais ou a menos a uma determinada escola, porém, a fama e o certo renome que ela ganha, ainda que em escala simples como a de um bairro, podem interferir na intensidade de procura por matrículas. Nesse sentido, ainda segundo o autor, as escolas que obtêm bons resultados nesses tipos de avaliações tendem a ter grande demanda por matrículas, porém a prefeitura atua para limitar o número de vagas delas, ao passo que as que tenham resultados abaixo do esperado recebem a superlotação, oriunda das barreiras que a maioria dos responsáveis de alunos encontram nas (poucas) escolas de maior prestígio. Assim, o poder público, ao atribuir valor qualitativo a suas escolas, além de alimentar a esperança de ascensão social a uma pequena camada da população mais vulnerável, conforme argumenta Bourdieu 
(2003), restringe o direito da liberdade de escolha dessa camada, intensificando desigualdades no acesso a setores como a educação.

Não obstante, a partir dos supracitados autores, análises dos medidores educacionais das escolas da $2^{a}$ CRE e, posteriormente, da região da Grande Tijuca fizeram-se necessárias. Consultou-se os resultados do IDEB, medido a partir da Prova Brasil - avaliações exclusivamente das disciplinas de Português e Matemática em formato de prova bimestral, duas vezes a cada dois anos. A amostra corresponde ao período entre os anos de 2007 a 2017, compreendendo a primeira e a última Prova Brasil aplicada a escolas municipais, analisada a partir de informações dos censos escolares. O recorte se mostra pertinente, além disso, pois considera-se aqui o tempo de 10 anos como um possível peso no prestígio escolar (DA COSTA, 2008), tanto em aspecto positivo como negativo.

Tabela 4: Ranking do IDEB médio entre os anos de 2007 e 2017 das escolas da $2^{\mathrm{a}}$ CRE que possuem ensino fundamental II.

\begin{tabular}{|c|c|}
\hline Escola & Ideb Médio (2007, 2009, 2011, 2013, 2015 e 2017) \\
\hline ESCOLA MUNICIPAL MINAS GERAIS & 5,75 \\
\hline ESCOLA MUNICIPAL ESTACIO DE SA & 5,733333333 \\
\hline ESCOLA MUNICIPAL AFFONSO PENNA & 5,616666667 \\
\hline ESCOLA MUNICIPAL DOUTOR COCIO BARCELLOS & 5,433333333 \\
\hline ESCOLA MUNICIPAL MADRID & 5,3 \\
\hline ESCOLA MUNICIPAL ROMA & 5,233333333 \\
\hline ESCOLA MUNICIPAL GENERAL EUCLYDES DE & 5,216666667 \\
\hline FIGUEIREDO & 5,166666667 \\
\hline ESCOLA MUNICIPAL ANDRE URANI & 5,033333333 \\
\hline ESCOLA MUNICIPAL MANOEL CICERO & 4,983333333 \\
\hline ESCOLA MUNICIPAL JOAO SALDANHA & 4,916666667 \\
\hline ESCOLA MUNICIPAL FRANCISCO MANUEL & 4,916666667 \\
\hline ESCOLA MUNICIPAL ORSINA DA FONSECA & 4,85 \\
\hline ESCOLA MUNICIPAL EPITACIO PESSOA & 4,8 \\
\hline ESCOLA MUNICIPAL PANAMA & 4,766666667 \\
\hline ESCOLA MUNICIPAL CHRISTIANO HAMANN & 4,766666667 \\
\hline ESCOLA MUNICIPAL FRANCISCO CABRITA & 4,533333333 \\
\hline ESCOLA MUNICIPAL CASTELNUOVO & 4,5 \\
\hline ESCOLA MUNICIPAL PROFESSOR LOURENCO & 4,466666667 \\
\hline FILHO & 4,3 \\
\hline ESCOLA MUNICIPAL JOSE DE ALENCAR & 4,166666667 \\
\hline ESCOLA MUNICIPAL PRESIDENTE JOAO & 4,116666667 \\
\hline GSCOLA MUNICIPAL JOAQUIM NABUCO & 4,05 \\
\hline ESCOLA MUNICIPAL SAO TOMAS DE AQUINO & \\
\hline
\end{tabular}




\begin{tabular}{|c|c|}
\hline ESCOLA MUNICIPAL DEODORO & 4 \\
\hline $\begin{array}{c}\text { ESCOLA MUNICIPAL PRESIDENTE ARTHUR DA } \\
\text { COSTA E SILVA }\end{array}$ & 3,966666667 \\
\hline ESCOLA MUNICIPAL MARILIA DE DIRCEU & 3,916666667 \\
\hline ESCOLA MUNICIPAL MARC FERREZ & 3,916666667 \\
\hline $\begin{array}{c}\text { ESCOLA MUNICIPAL GENERAL DO EXERCITO } \\
\text { HUMBERTO DE SOUZA MELLO }\end{array}$ & 3,866666667 \\
\hline $\begin{array}{c}\text { ESCOLA MUNICIPAL DESEMBARGADOR OSCAR } \\
\text { TENORIO }\end{array}$ & 3,8 \\
\hline ESCOLA MUNICIPAL ARAUJO PORTO ALEGRE & 3,783333333 \\
\hline ESCOLA MUNICIPAL ALENCASTRO GUIMARAES & 3,683333333 \\
\hline ESCOLA MUNICIPAL EQUADOR & 3,683333333 \\
\hline ESCOLA MUNICIPAL FRANCISCO CAMPOS & 3,666666667 \\
\hline ESCOLA MUNICIPAL JOAQUIM ABILIO BORGES & 3,666666667 \\
\hline ESCOLA MUNICIPAL SOARES PEREIRA & 3,65 \\
\hline ESCOLA MUNICIPAL REPUBLICA ARGENTINA & 3,583333333 \\
\hline ESCOLA MUNICIPAL GEORGE PFISTERER & 3,53333333 \\
\hline ESCOLA MUNICIPAL LAUDIMIA TROTTA & 3,416666667 \\
\hline ESCOLA MUNICIPAL JORNALISTA ASSIS & 3,35 \\
\hline CHATEAUBRIAND & 3,34 \\
\hline ESCOLA MUNICIPAL REVERENDO MARTIN & 3,333333333 \\
\hline LUTHER KING & 3,3 \\
\hline ESCOLA MUNICIPAL CAMILO CASTELO BRANCO & 3,25 \\
\hline ESCOLA MUNICIPAL HENRIQUE DODSWORTH & 1,375 \\
\hline ESCOLA MUNICIPAL ALMIRANTE TAMANDARE & \\
\hline CIEP PRESIDENTE JOAO GOULART & \\
\hline
\end{tabular}

Legenda:

Não compreende os bairros da Grande Tijuca

Situada na Grande Tijuca, mas não faz parte da parceria

Faz parte da parceria

Fonte: censo escolar.

Como é possível notar, a partir da tabela 4, o projeto Turma Cidadã tem três de suas 8 escolas entre os 10 melhores IDEB de toda a região da $2^{\text {a }}$ CRE, a E.M. Madrid (5 $)$, a E.M. Euclydes Figueiredo $\left(7^{\circ}\right)$ e a E.M. Barão de Itacurussá $\left(9^{\circ}\right)$. Em sequência, é possível notar a presença de outras 4 escolas entre as 20 mais bem ranqueadas, a E.M. Francisco Manuel $\left(12^{\circ}\right)$, a E.M. Orsina da Fonseca $\left(13^{\circ}\right)$, a E.M. Epitácio Pessoa $\left(14^{\circ}\right)$ e a E.M. Francisco Cabrita $\left(17^{\circ}\right)$. Nesse sentido, ainda que preliminarmente, esse dado avaliativo da educação aparece como pertinente para compreender um dos critérios utilizados pela SME para seleção do alunado do projeto. 
Tabela 5: ranking do IDEB na região da Grande Tijuca.

\begin{tabular}{|c|c|c|}
\hline ESCOLA & IDEB (média 10 anos) & Distância ao CEFET \\
\hline ESCOLA MUNICIPAL AFFONSO PENNA & 5,616666667 & $5,5 \mathrm{~km}$ \\
\hline ESCOLA MUNICIPAL MADRID & 5,3 & $2,2 \mathrm{~km}$ \\
\hline FSCOLA MUNICIPAL GENERAL EUCLYDES DE & 5,216666667 & $2,3 \mathrm{~km}$ \\
\hline ESCOLA MUNICIPAL BARAO DE ITACURUSSA & 5,033333333 & $2,8 \mathrm{~km}$ \\
\hline ESCOLA MUNICIPAL FRANCISCO MANUEL & 4,916666667 & $1,0 \mathrm{~km}$ \\
\hline ESCOLA MUNICIPAL ORSINA DA FONSECA & 4,85 & $5,0 \mathrm{~km}$ \\
\hline ESCOLA MUNICIPAL EPITACIO PESSOA & 4,8 & $2,0 \mathrm{~km}$ \\
\hline ESCOLA MUNICIPAL FRANCISCO CABRITA & $4,4 \mathrm{~km}$ \\
\hline ESCOLA MUNICIPAL PRESIDENTE JOAO GOULART & 4,166666667 & $4,3 \mathrm{~km}$ \\
\hline ESCOLA MUNICIPAL GENERAL DO EXERCITO HUMBERTO & 3,866666667 & $5,9 \mathrm{~km}$ \\
\hline ESCOLA MUNICIPAL EQUADOR & 3,683333333 & $4,4 \mathrm{~km}$ \\
\hline ESCOLA MUNICIPAL SOARES PEREIRA & 3,65 & $3,0 \mathrm{~km}$ \\
\hline ESCOLA MUNICIPAL REPUBLICA ARGENTINA & 3,583333333 & $3,4 \mathrm{~km}$ \\
\hline ESCOLA MUNICIPAL LAUDIMIA TROTTA & 3,416666667 & $8,9 \mathrm{~km}$ \\
\hline ESCOLA MUNICIPAL REVERENDO MARTIN LUTHER KING & 3,35 & $1,7 \mathrm{~km}$ \\
\hline
\end{tabular}

Legenda:

Não faz parte do convênio
Faz parte do convênio

Fonte: Censo escolar e Google Earth.

A partir da tabela 5, analisando o ranqueamento médio do IDEB na região da Grande Tijuca, é possível constatar que esse dado foi, portanto, o determinante para a seleção das escolas que fariam parte do convênio com o CEFET. Em relação a última colocada nesse ranking, a E.M. Reverendo Martin Luther King, embora seja considerada como participante do projeto, a instituição teve apenas 1 aluno selecionado, no ano de lançamento do pré-técnico social e, segundo os coordenadores, a pedido do próprio CEFET em virtude da já comentada proximidade entre ambas escolas. Não obstante, sob o contexto em que apenas um estudante foi cedido por uma instituição que, embora muito próxima ao CEFET, possui o IDEB médio mais baixo entre todas as escolas que possuem ensino fundamental II na Grande Tijuca, tendo por consequência o baixo prestígio escolar.

Após a análise sobre os mecanismos de seleção de escolhas para participação no convênio, a presente pesquisa se propôs a realizar um terceiro trabalho de campo, agora em 
uma das escolas compreendidas na região da Grande Tijuca, também filiada à $2^{a} \mathrm{CRE}$, mas que não faz parte da parceria. Em entrevista semi-estruturada ao coordenador pedagógico, diretora adjunta e diretora geral dessa escola que, por razões metodológicas, será mantida em anonimato, foram elaboradas questões referentes à ausência dessa instituição no projeto, visando compreender as razões pelas quais uma escola próxima ao CEFET não estaria sendo contemplada. No entanto, os três entrevistados disseram desconhecer o convênio, mas o vêem positivamente, afirmando que gostariam de indicar, pelo menos, cinco de seus estudantes para participarem do pré-técnico social. Não obstante, afirmaram que em momento algum foram procurados pela CRE para tratar desse assunto, mas buscariam o diálogo para firmar acordo para o próximo ano letivo.

Nesse sentido, a partir da análise dos dados coletados, é possível afirmar que o Projeto Turma Cidadã, ao conceder autonomia à Secretaria Municipal de Educação do Rio de Janeiro, ratifica as desigualdades criadas e mantidas por esse sistema. Em um complexo jogo de escalas, orientada por um viés meritocrático, a $2^{\mathrm{a}} \mathrm{CRE}$ intensifica e legitima a exclusão social e, sendo pertencente ao Estado capitalista, corrobora para a manutenção das desigualdades, potencializa os processos de precarização territorial e nega o direito à cidade para a maioria do seu alunado, pois bonifica as escolas que já possuem bons resultados e prestígio, optando por um restrito número de estudantes para terem a oportunidade eventual de ascensão social.

\section{O acompanhamento dos ex-alunos do projeto de extensão}

Finalmente, na presente seção, a partir da análise de dados coletados em campo, será possível discutir como o pré-técnico social interferiu no desempenho dos estudantes que tenham sido aprovados no concurso público de seleção para o ensino médio-técnico do CEFET/RJ. Não obstante também será minimamente discutida a eficácia no que tange às aprovações em outros processos seletivos.

A motivação dessa análise é a verificação do êxito que o próprio CEFET diz almejar, ou seja, se a partir das aulas assistidas no pré-técnico, o desempenho desse novo público de alunos melhorou a ponto de garantir sua permanência no ensino médio da instituição. Por 
outro lado, não se pretende discutir aqui sobre as maneiras como a parceria influenciou na formação dos estudantes enquanto cidadãos, mas será possível apresentar alguns dos resultados obtidos em aprovações de seus alunos nesse e em outros processos seletivos para escola de maior prestígio.

\section{Gráfico 3: desempenho dos ex-alunos do pré-técnico da turma de 2017 no CEFET/RJ.}

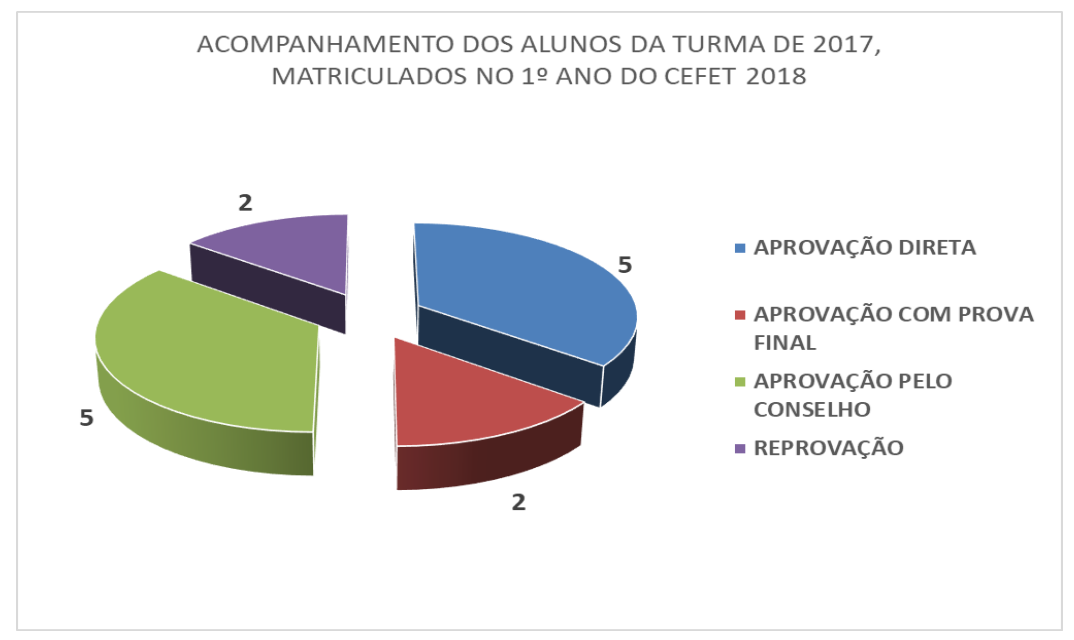

Fonte: DEMET-CEFET.

Em relação ao desempenho dos ex-alunos do pré-técnico social no ensino médiotécnico no CEFET, caso tenham sido aprovados na seleção, só foi possível obter os dados referentes à turma de 2017, ou seja, aqueles estudantes que tenham iniciado a jornada na instituição federal em 2018. De acordo com a coordenação, os dados referentes ao $2^{\circ}$ ano desses estudantes e, consequentemente, também os da turma de 2018 do pré-técnico ainda estavam sendo trabalhados neste ano de 2019. No entanto, como é possível notar a partir do gráfico 3, a turma do ano de 2017 da parceria teve 14 estudantes aprovados no concurso público e matriculados na escola técnica.

A partir do universo de 14 estudantes supracitado, é possível notar que, ao final do primeiro ano letivo no ensino médio-técnico do CEFET, 5 (cinco) tiveram aprovação direta em todas as disciplinas, 2 (dois) foram aprovados para a série seguinte a partir da prova final, ao passo que outros 2 (dois) foram aprovados pelo conselho de classe, mesmo tendo reprovado por média após a prova final e, por fim, 2 (dois) foram reprovados e estão tendo que cursar novamente o $1^{\circ}$ ano do ensino médio-técnico em 2019. É possível dizer que, de forma geral, 
há uma tendência para a maioria dos ex-alunos conquistarem a aprovação, mas chama a atenção

o fato que entre os 14, um total de 4 não obteve a média necessária, mesmo após a prova final.

Tabela 6: escolas de origem e destino dos alunos do pré-técnico na turma de 2017.

\begin{tabular}{|c|c|}
\hline ESCOLA DE ORIGEM (2017) & DESTINO (2018) \\
\hline \multirow{10}{*}{ E.M. Barão Itacurussá (10 alunos) } & Bolsa de $100 \%$ MV1 \\
\hline & Bolsa de $100 \%$ PALLAS \\
\hline & CEFET - Meteorologia - Manhã \\
\hline & Bolsa de $100 \%$ Ícaro \\
\hline & IFRJ \\
\hline & Sem informação \\
\hline & CEFET - Eletrotécnica - Tarde \\
\hline & CEFET - Eletrotécnica - Tarde \\
\hline & CEFET - Eletrônica - Tarde \\
\hline & Bolsa de $100 \%$ MV1 \\
\hline \multirow{7}{*}{ E.M. Epitácio Pessoa (7 alunos) } & NAVE \\
\hline & IFRJ \\
\hline & Bolsa de $100 \%$ PALLAS \\
\hline & CEFET - Edificações - Manhã \\
\hline & IFRJ \\
\hline & CEFET - Informática - Tarde \\
\hline & Bolsa de $100 \%$ Pallas \\
\hline \multirow{10}{*}{ E.M. Francisco Cabrita (10 alunos) } & Antônio Prado Junior \\
\hline & Sem informação \\
\hline & Sem informação \\
\hline & Bolsa de $100 \%$ MV1 \\
\hline & CEFET/MG - Manutenção Automotiva - Tarde \\
\hline & NAVE \\
\hline & Visconde de Cairu \\
\hline & Ferreira Vianna \\
\hline & Sem informação \\
\hline & Sem informação \\
\hline \multirow{8}{*}{ E.M. Francisco Manuel (8 alunos) } & Bolsa de $100 \%$ MV1 \\
\hline & Sara Kubistchek \\
\hline & Bolsa de $100 \%$ MV1 \\
\hline & Aprov. CEFET(Perdeu a reclassificação) - Bolsa de $100 \%$ MV1 \\
\hline & CEFET - Informática - Manhã \\
\hline & FAETEC \\
\hline & CEFET - Informática - Manhã \\
\hline & Antônio Prado Junior \\
\hline \multirow{4}{*}{$\begin{array}{c}\text { E.M. Gal Euclydes de Figueiredo (8 } \\
\text { alunos) }\end{array}$} & FAETEC \\
\hline & Herbert de Souza \\
\hline & Bolsa de $100 \%$ PENSI \\
\hline & Bolsa de $100 \%$ PENSI \\
\hline
\end{tabular}




\begin{tabular}{|c|c|}
\hline & Colégio Estadual Herbert de Souza \\
\hline & CEFET - Edificações - Manhã \\
\hline & Bolsa de $100 \%$ PALLAS \\
\hline & Bolsa de $100 \%$ Ao Cubo \\
\hline \multirow{8}{*}{ E.M. Madrid (8 alunos) } & Fundação VENCER \\
\hline & CEFET - Administração - Tarde \\
\hline & Sem informação \\
\hline & CEFET - Meteorologia - Manhã \\
\hline & Colégio Estadual Chico Anysio \\
\hline & IFRJ \\
\hline & CEFET - Informática - Tarde \\
\hline & FAETEC \\
\hline \multirow{9}{*}{ E.M. Orsina da Fonseca (9 alunos) } & NAVE \\
\hline & NAVE \\
\hline & Sem informação \\
\hline & CEFET/NI - Enfermagem - Integral \\
\hline & Sem informação \\
\hline & Sem informação \\
\hline & Antônio Prado Junior \\
\hline & CEFET - Meteorologia - Manhã \\
\hline & Sem informação \\
\hline $\begin{array}{c}\text { E.M. Ver. Marthin Luther King (1 } \\
\text { aluno) }\end{array}$ & Antônio Prado Junior \\
\hline
\end{tabular}

Fonte: coordenação do pré-técnico social.

Tabela 7: escolas de origem e destino dos alunos do pré-técnico

\begin{tabular}{|c|c|}
\hline Escola de origem (2018) & Destino (2019) \\
\hline \multirow{10}{*}{ E.M. Barão Itacurussá (10 alunos) } & CEFET ADMINISTRAÇÃO TARDE \\
\hline & COLÉGIO ESTADUAL CHICO ANYSIO \\
\hline & COLÉGIO ESTADUAL HERBERT DE SOUZA \\
\hline & COLÉGIO ESTADUAL JOÃO ALFREDO \\
\hline & ESCOLA TÉCNICA FERREIRA VIANA \\
\hline & NAVE \\
\hline & PALLAS $100 \%$ \\
\hline & PALLAS $100 \%$ \\
\hline & PALLAS $100 \%$ \\
\hline & $\begin{array}{l}\text { PENSI } 100 \% \\
\end{array}$ \\
\hline \multirow{8}{*}{ E.M. Epitácio Pessoa (8 alunos) } & COLÉGIO ESTADUAL CHICO ANYSIO \\
\hline & CEFET ELETRÔNICA TARDE \\
\hline & CEFET ELETRÔNICA TARDE \\
\hline & CEFET INFORMÁTICA TARDE \\
\hline & CEFET INFORMÁTICA TARDE \\
\hline & COLÉGIO ESTADUAL CHICO ANYSIO \\
\hline & ESCOLA TÉCNICA FERREIRA VIANA \\
\hline & NAVE \\
\hline E.M. Francisco Cabrita (11 alunos) & COLÉGIO ESTADUAL JULIA KUBITSCHECK \\
\hline
\end{tabular}




\begin{tabular}{|c|c|}
\hline & CEFET EDIFICAÇÕES TARDE \\
\hline & CEFET EDIFICAÇÕES TARDE \\
\hline & CEFET ELETRÔNICA TARDE \\
\hline & COLÉGIO ESTADUAL HERBERT DE SOUZA \\
\hline & COLÉGIO ESTADUAL IGNÁCIO AZEVEDO DO AMARAL \\
\hline & COLÉGIO ESTADUAL PAULO DE FRONTIN \\
\hline & COLÉGIO ESTADUAL PRADO JUNIOR \\
\hline & ÍCONE $40 \%$ \\
\hline & NAVE \\
\hline & SEM INFORMAÇÃO \\
\hline \multirow{8}{*}{ E.M. Francisco Manuel (8 alunos) } & COLÉGIO ESTADUAL CHICO ANYSIO \\
\hline & CEFET EDIFICAÇÕES TARDE \\
\hline & CEFET ELETRÔNICA TARDE \\
\hline & CEFET ESTRADAS MANHÃ \\
\hline & COLÉGIO ESTADUAL PRADO JUNIOR \\
\hline & COLÉGIO ESTADUAL PRADO JUNIOR \\
\hline & ESCOLA TÉCNICA FERREIRA VIANA \\
\hline & SEM INFORMAÇÃO \\
\hline \multirow{5}{*}{$\begin{array}{c}\text { E.M. Gal Euclydes de Figueiredo (5 } \\
\text { alunos) }\end{array}$} & ESCOLA TÉCNICA FERREIRA VIANA \\
\hline & CEFET SEG TRAB TARDE \\
\hline & COLÉGIO ESTADUAL JULIA KUBITSCHECK \\
\hline & COLÉGIO ESTADUAL PAULO DE FRONTIN \\
\hline & SEM INFORMAÇÃO \\
\hline \multirow{10}{*}{ E.M. Madrid (10 alunos) } & FIO CRUZ \\
\hline & AO CUBO $100 \%$ \\
\hline & CEFET EDIFICAÇÕES TARDE \\
\hline & COLÉGIO ESTADUAL CHICO ANYSIO \\
\hline & COLÉGIO ESTADUAL HERBERT DE SOUZA \\
\hline & COLÉGIO ESTADUAL HERBERT DE SOUZA \\
\hline & COLÉGIO ESTADUAL HERBERT DE SOUZA \\
\hline & COLÉGIO PEDRO II \\
\hline & PENSI $100 \%$ \\
\hline & PENSI $100 \%$ \\
\hline \multirow{9}{*}{ E.M. Orsina da Fonseca (9 alunos) } & CEFET ADMINISTRAÇÃO TARDE \\
\hline & CEFET EDIFICAÇÕ \\
\hline & CEFET EDIFICAÇÕ̃ES MANHÃ \\
\hline & CEFET EDIFICAÇÕES MANHÃ \\
\hline & CEFET EDIFICAÇÕES TARDE \\
\hline & CEFET ELETROTÉCNICA TARDE \\
\hline & CEFET- $\mathrm{M}^{a}$ G MANUT AUTO TARDE \\
\hline & ESCOLA TÉCNICA ADOLPH BLOCH \\
\hline & IFRJ \\
\hline
\end{tabular}

Fonte: coordenação do pré-técnico social.

As tabelas 6 e 7 são referentes às escolas de origem, ou seja, aquelas onde os estudantes do pré-técnico social estudavam no contraturno, e às escolas para as quais eles se matricularam no ano seguinte para cursar o ensino médio. Dois pontos são fundamentais sobre esses dados: 1) em ambos os anos, é possível observar uma tendência de aprovação desse alunos em 
processos seletivos para o ensino médio, seja em escolas públicas com maior renome como o próprio CEFET, Colégio Pedro II, FAETEC, IFRJ e NAVE, por exemplo, seja também em escolas particulares, obtendo bolsas de 100\% na mensalidade; 2) o número de aprovações para o CEFET aumentou de 2017 para 2018, de 15 para 20 estudantes. Além da variação indicar certa melhoria no que tange a aprovação no concurso, ela resulta em uma amostra ainda maior para uma análise futura sobre o desempenho desses novos alunos ao longo do ensino médiotécnico da instituição.

\section{Conclusão}

A descrição de Souza (2017) sobre a divisão de classes sociais no Brasil, especialmente a chamada pelo autor como "ralé brasileira", nos permite identificar mazelas históricas que semearam e, com devidas adaptações conjunturais, acentuam e intensificam as desigualdades a partir de competições desequilibradas. No mesmo sentido, sobretudo a partir de Bourdieu (2003), é possível compreender que um dos instrumentos ratificadores desse sistema é a educação, pois conserva as escolas que possibilitam a obtenção de capital cultural às elites e à classe média. A partir desses autores, é possível notar que o sistema educacional brasileiro e, no caso do presente trabalho, especificamente o do município do Rio de Janeiro, possui valores implícitos e interiorizados que norteiam a gestão de suas escolas e alunos a partir de critérios meritocráticos.

No caso do presente trabalho, analisando seus dois agentes ativos na efetivação do convênio, o CEFET/RJ e a $2^{\text {a }}$ Coordenadoria de Educação do Município do Rio de Janeiro, é possível associar suas atuações com o descrito por Freire (1987), Bourdieu (2003), Da Costa, Do Prado e Rosistolato (2012) e por Da Costa (2008). O CEFET, por ser uma instituição de renome, pública, mas detentora de uma histórica burocracia elitista e excludente, como é o seu processo de admissão de alunos ao ensino médio-técnico por meio de provas, é uma escola de bom prestígio e, não obstante, oferece possibilidades de aquisição de capital cultural para aqueles que nela conseguem estudar. Ao se adequar à Lei de reserva de vagas às ações afirmativas ( $\left.\mathrm{n}^{\circ} 12.711 / 2012\right)$, passa a oferecer seu capital cultural a outras classes sociais, mas se mostra irredutível quanto à permanência desses novos alunos até o fim de seus estudos no 
ensino básico. Não obstante, apresenta argumentos que, segundo os dados fornecidos ao presente trabalho, não se justificam à alarmante preocupação com possíveis aumentos de reprovação e, posteriormente, jubilamentos. No entanto, ao criar a parceria com a Secretaria Municipal de Educação e não interferir diretamente na seleção de alunos e escolas, visando uma democratização ainda maior do acesso, acaba por privilegiar estudantes de instituições que já recebem tratamento privilegiado pela prefeitura, assumindo passivamente um papel fundamental na manutenção de um sistema educacional estratificado.

Bourdieu (2003) descreve a Escola Conservadora como uma instituição tradicional, elitista e excludente, detentora e propagadora de uma cultura aristocrática, pois trata os diferentes de maneira igual. Assim, ainda segundo o autor, admite um tipo de aluno padrão em geral, aquele já detentor de maior capital cultural - legitimando as desigualdades que, antes de tudo, são de origem social. Essas são as características do que o autor chama de processo de indiferença pedagógica da Escola Conservadora. No entanto, com devidas adaptações, o debate feito pelo autor poderia ser adaptado ao sistema educacional brasileiro e resume de maneira sintética os privilégios e as exclusões presentes no convênio entre o CEFET e a $2^{\mathrm{a}}$ CRE.

No mesmo sentido, apesar de interessante a iniciativa de um projeto de extensão entre instituições de ensino municipal e federal, no contexto descrito por esse trabalho, ele intensifica a desigualdade. Pois, escolas da mesma região da Tijuca são deixadas de lado a partir de critérios pouco transparentes, assim como estudantes de escolas em outros bairros da $2^{\mathrm{a}}$ CRE e, certamente, potenciais candidatos de colégios municipais de outras áreas do Rio de Janeiro que, apesar de também terem direito às cotas, nem sequer sabem da existência do convênio. Em caso de conhecimento dos responsáveis pelos alunos, se tiverem seus filhos matriculados em escolas que estejam dentre as excluídas pela parceria, é possível afirmar, a partir de Da Costa, Do Prado e Rosistolato (2012) que o reconhecimento da impossibilidade se fará, mais uma vez, presente: "não é para mim".

"Quem, melhor que os oprimidos, se encontrará preparado para entender o significado terrível de uma sociedade opressora? Quem sentirá, melhor que eles, os efeitos da opressão? Quem, mais que eles, para ir compreendendo a necessidade da libertação? Libertação a que não chegarão pelo acaso, mas pela práxis de sua busca; pelo conhecimento e reconhecimento da necessidade de 
lutar por ela. Luta que, pela finalidade que lhe derem os oprimidos, será um ato de amor, com o qual se oporão ao desamor contido na violência dos opressores, até mesmo quando esta se revista da falsa generosidade referida" (FREIRE, 1987. p. 20).

\section{Referências}

ABREU, Maurício de A. Evolução urbana do Rio de Janeiro. 1987.

BEAUJEU-GARNIER, Jacqueline. Geografia Urbana. 2. Edição. Lisboa, Fundação Calouste Gulbenkian, 1995.

BOURDIEU, Pierre. A escola conservadora: as desigualdades frente à escola e à cultura. Escritos de Educação. Petrópolis: Vozes, p. 39-64, 2003.

CARLOS, Ana Fani Alessandri. O direito à cidade e a construção da metageografia. Revista Cidades, v. 2, n. 4, 2005.

CORRÊA, Roberto Lobato. O espaço urbano. São Paulo: Ática, 1989.

Geografia: conceitos e temas. Brasil: Editora Bertrand, 1995

COSTA, Rogerio Haesbaert. Território e multiterritorialidade: um debate. Antares. 2007.

Regional-global: dilemas da região e da regionalização na geografia contemporânea. Rio de Janeiro: Bertrand Brasil, 2010.

DA COSTA, Marcio. Prestígio e hierarquia escolar: estudo de caso sobre diferenças entre escolas em uma rede municipal. Revista Brasileira de Educação, v. 13, n. 39, p. 455-469, 2008.

DA COSTA, Marcio; DO PRADO, Ana Pires; ROSISTOLATO, Rodrigo. "Talvez se eu tivesse algum conhecimento...": caminhos possíveis em um sistema educacional público e estratificado. Interseções: Revista de Estudos Interdisciplinares, v. 14, n. 1, 2012.

FREIRE, Paulo. Pedagogia do oprimido. 17 a . Ed. Rio de Janeiro: Paz e Terra, v. 3, p. 36, 1987.

HARVEY, David. Class Structure in a Capitalist Society and the Theory of Residential Differentation. Heinemann, 1975.

INEP. Censos escolares 2007-2018. Disponível em: <http://inep.gov.br/web/guest/censoescolar $>$

Portal carioca digital. Lista de escolas da secretaria municipal de educação. Disponível em: <http://www.rio.rj.gov.br/web/sme/exib econteudo?article-id=96302>

SCHLOSBERG, David. Defining Environmental Justice: Theories, Movements, and Nature. Oxford: Oxford University Press, 2009.

SOUZA, Ana Carolina Duarte. Política de ação afirmativa no ensino médio: Estudo de caso no Cefet Maracanã - Rio de Janeiro Faculdade de Educação, Universidade Federal do Rio de Janeiro, 2016.

SOUZA, Jessé. A elite do atraso. Rio de Janeiro: Leya, 2017.

SOUZA, Marcelo Lopes de. Os conceitos fundamentais da pesquisa sócio-espacial. Bertrand Brasil, 2013. 
SPOSITO, Maria Encarnação. Capitalismo e urbanização. São Paulo: Hucitec, 1988. 